\title{
Metabolic Syndrome among Undergraduate Students Attending Medical Clinics for Obligatory Medical Screening
}

\author{
Ahmed Mohammed Ahmed ${ }^{1 *}$, Bader Eldien Hassan Elabid ${ }^{3}$, Kamal Eldin \\ Hussein Elhassan ${ }^{2}$ and Hisham Ali Waggiallah ${ }^{1}$ \\ ${ }^{1}$ Laboratory Department, College of Applied Medical Sciences, ${ }^{2}$ Department of Community Medicine - College of Medicine, \\ Taibah University, Almadinah Almunawara, Kingdom of Saudi Arabia, ${ }^{3}$ College of Medical Laboratory Sciences, University of \\ Science and Technology, Khartoum, Sudan
}

*For correspondence: Email: ahmedlab1@hotmail.com

\begin{abstract}
Purpose: To determine the prevalence and risk factors for metabolic syndrome (MS) among first-year undergraduate students in three Sudanese universities.

Methods: A total of 384 first-year students attending university medical clinics for obligatory medical checkup in Khartoum, Sudan participated in this cross-sectional study. Anthropometric parameters, including weight, height, body mass index (BMI) and waist circumference (WC) were measured with reference to National Cholesterol Education Program's Adult Treatment Panel III (NCEP/ATP III) guidelines. Fasting blood samples were collected from all participants and assayed for fasting blood glucose (FBG), total cholesterol (TC), triglyceride (TG), high density lipoprotein (HDL), and low density lipoprotein (LDL).

Results: The overall prevalence of MS in the test group was $7.8 \%$. The prevalence of MS, though higher in females, was statistically not significant $(p=0.32)$. According to residential area (rural urban), the prevalence was higher in urban than rural, 10.4 and $4.4 \%$, respectively $(p=0.25$ and $p=$ 0.25 , respectively). In addition, frequency of MS was directly proportional to age. The weight of patients with MS was significantly different from that of non-MS subjects $(p<0.001)$. Same was also observed when obese patients were compared with non-MS subjects. $(p<0.001)$.

Conclusion: The prevalence of MS among Sudanese first-year university students in Khartoum is moderately high. Incidence of MS among the students is directly proportional to BMI.
\end{abstract}

Keywords: Metabolic syndrome, Obesity, Hypertension, Diabetes, Dyslipidemia, Anthropometric

Tropical Journal of Pharmaceutical Research is indexed by Science Citation Index (SciSearch), Scopus, International Pharmaceutical Abstract, Chemical Abstracts, Embase, Index Copernicus, EBSCO, African Index Medicus, JournalSeek, Journal Citation Reports/Science Edition, Directory of Open Access Journals (DOAJ), African Journal Online, Bioline International, Open-J-Gate and Pharmacy Abstracts

\section{INTRODUCTION}

Metabolic syndrome (MS) as a constellation of risk factors that increase a person's risk of developing cardiovascular diseases (CVD), including central obesity, insulin resistance, dyslipidemia and hypertension [1,2]. MS is rapidly increasing in prevalence with rising childhood obesity and sedentary lifestyles worldwide [3]. It is $a$ is a risk factor for non- communicable diseases, such as diabetes mellitus and cardiovascular disease, which are world's biggest killer diseases, estimated to cause 3.5 million deaths each year. Overweight and obesity are risk factors for coronary artery disease, hypertension and DM; however, not everyone with these conditions is obese and not all obese people have these conditions. 
National Cholesterol Education Program's Adult Treatment Panel III (NCEP/ATP III) defined MS as the presence of three or more of any of the following criteria in an individual: high waist circumference (WC), elevated fasting glucose (GLU), low high-density lipoprotein cholesterol (HDL-C), elevated triglycerides (TG) and elevated blood pressure (BP) [4].

However, very few studies on MS have been done in Sudan. This study was conducted in undergraduate university students to estimate prevalence and risk factors of the MS using NCEP/ATP III protocols. The study group was selected from first-year students because they are required to undergo an obligatory medical examination in the university clinics before commencing their studies in the university. MS is considered a risk factor for the incidence of atherosclerosis and artery diseases as shown by several studies [5-7]. Therefore, the objective of the study was to determine the prevalence of MS in undergraduate students in study area.

\section{METHODS}

\section{Subjects}

Three hundred eighty four healthy first-year undergraduate students (273 males, 111 females, aged between 18 and 23 years) in Khartoum, Sudan were enrolled in the study. The students attended the medical clinics of their respective institutions for obligatory medical screening from August - October 2013. Three universities were randomly selected from the 15 campuses in the city. The participating students were selected by systematic random method.

\section{Anthropometric parameters}

BMI $\left(\mathrm{kg} / \mathrm{cm}^{2}\right)$ and WC (weight circumference) were measured following the guidelines of NCEP/ATP III [5]. BMI was calculated using the ratio of weight in kilograms to height in meters $\left(\mathrm{kg} / \mathrm{m}^{2}\right)$. BMI classifications used were underweight $\left(<18.5 \mathrm{~kg} / \mathrm{m}^{2}\right)$, normal $(18.5-24.9$ $\left.\mathrm{kg} / \mathrm{m}^{2}\right)$, overweight $\left(25-29.9 \mathrm{~kg} / \mathrm{m}^{2}\right)$, and obese $\left(\geq 30.0 \mathrm{~kg} / \mathrm{m}^{2}\right)$. WC was measured at the top of the iliac crest upon exhalation to the nearest 0.1 $\mathrm{cm}$ using Gulick fiberglass, non-stretchable tape measure with a tensometer (average of two measurements) (Patterson Medical, Mount Joy, PA).

\section{Clinical and biochemical parameters}

Systolic and diastolic blood pressure were recorded (in $\mathrm{mm} \mathrm{Hg}$ ) using manual monitor; measurements were performed in sitting position, recorded in duplicate, every $5 \mathrm{~min}$. Fasting venous blood samples were collected from students for measurement of fasting blood glucose (FBG), total cholesterol (TC), triglycerides (TG), high density lipoprotein (HDL) and low density lipoprotein (LDL). All measurements were carried out using enzymatic methods using Hitachi autoanalyzer 704 (Roche Diagnostics Switzerland). Students with diabetes, hypertension, and those taking continuous medications were excluded from the study. All these measurements were done by well trained staff of clinical units under supervision

\section{Criteria for MS}

NCEP/ATP III suggests that the clinical diagnosis of the MS is based upon the following: Increased abdominal fat WC was $>102 \mathrm{~cm}$ for males and $>$ $88 \mathrm{~cm}$ for females. Elevated TG was $\geq 150$ $\mathrm{mg} / \mathrm{dL}$ while low HDL-C was $<40 \mathrm{mg} / \mathrm{dL}$ for males and $<50 \mathrm{mg} / \mathrm{dL}$ for females. Elevated fasting GLU was $\geq 100 \mathrm{mg} / \mathrm{dL}$ and arterial BP was $\geq 130 / 85 \mathrm{mmHg}$.

\section{Statistical analysis}

Data was analysed using SPSS version 19. ChiSquare test was used to examine differences between BMI categorize. ANOVA test was used to determine the differences between groups. Fisher exact test for small expected cells was used $[\downarrow 5] . P \leq 0.05$ was considered significant for all tests.

\section{Ethical considerations}

The objectives of the study were explained to all students participating in this study, and an informed consent was obtained from all participants with the questionnaire. Ethical clearance was obtained from the Ethical Committee Board of the universities included in study.

\section{RESULTS}

The results for anthropometric characteristics, blood pressure and biochemical profile are summarized in Table 1 . Table 2 states the prevalence of MS categorized by age, gender, residential area and BMI. The weight of patients with MS was significantly different from that of non-MS subjects $(p<0.001)$. Same was also observed when obese patients were compared with non-MS subjects $(p<0.001)$. Figure 1 shows MS profiles categorized by gender. 
Table 1: Age, anthropometric, clinical and biochemical parameters of study group

\begin{tabular}{|c|c|c|c|c|}
\hline Variable & $\begin{array}{c}\text { Male } \\
\mathrm{N}=273\end{array}$ & $\begin{array}{c}\text { Female } \\
\mathrm{N}=111\end{array}$ & $\begin{array}{l}\text { Total } \\
\mathrm{N}=384\end{array}$ & $P$-value \\
\hline $\begin{array}{l}\text { Age } \\
\text { Anthropometric parameters }\end{array}$ & $20.1 \pm 1.2$ & $19.9 \pm 0.6$ & $20.0 \pm 0.8$ & 0.24 \\
\hline BMl $\left(\mathrm{kg} / \mathrm{cm}^{2}\right)$ & $22.6 \pm 2.3$ & $22.5 \pm 1.6$ & $22.5 \pm 2.1$ & 0.76 \\
\hline Waist circumference $(\mathrm{cm})$ & $76.6 \pm 6.9$ & $77.1 \pm 7.4$ & $76.8 \pm 6.2$ & 0.52 \\
\hline Blood pressure $(\mathrm{mm} / \mathrm{Hg})$ & & & & \\
\hline Systolic (mm Hg) & $121.0 \pm 8.1$ & $120.4 \pm 7.8$ & $121.0 \pm 9.7$ & 0.19 \\
\hline $\begin{array}{l}\text { Diastolic }(\mathrm{mm} \mathrm{Hg}) \\
\text { Metabolic profiles }\end{array}$ & $78.2 \pm 8.4$ & $78.0 \pm 6.9$ & $78.1 \pm 8.3$ & 0.49 \\
\hline Glucose (mg/dL) & $97.3 \pm 6.5$ & $96.5 \pm 5.4$ & $97.0 \pm 5.1$ & 0.22 \\
\hline Total cholesterol (mg/dL) & $164.2 \pm 18.3$ & $162.1 \pm 21.1$ & $163.6 \pm 19.5$ & 0.10 \\
\hline Triglyceride (mg/dL) & $83.6 \pm 9.6$ & $84.6 \pm 8.1$ & $83.8 \pm 8.2$ & 0.24 \\
\hline LDL (mg/dL) & $92.1 \pm 18.4$ & $90.5 \pm 19.1$ & $91.7 \pm 17.1$ & 0.12 \\
\hline $\mathrm{HDL}(\mathrm{mg} / \mathrm{dL})$ & $58.6 \pm 7.3$ & $57.1 \pm 7.3$ & $58.5 \pm 5.3$ & 0.21 \\
\hline
\end{tabular}

Note: Data shown are mean \pm standard deviation; $N=$ number; $B M I=$ body mass index; $W C=$ waist circumference; $T C=$ total cholesterol; $L D L=$ low-density lipoprotein cholesterol; $H D L=$ high-density lipoprotein cholesterol; TG = triglycerides; $G L U=$ glucose

Table 2: Prevalence of MS categorized by age groups, gender, residential area (rural or urban) and BMI

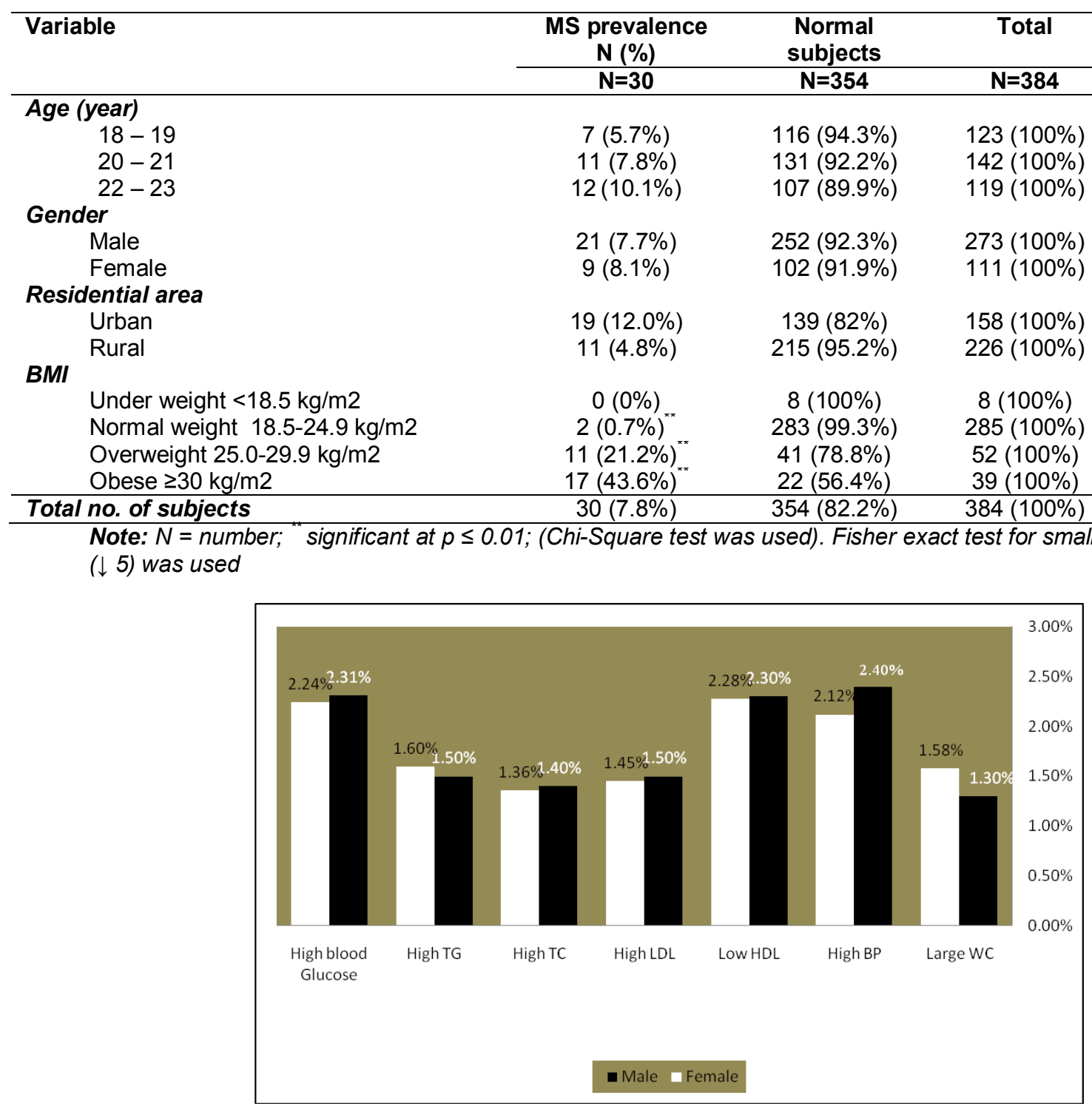

Figure 1: Anthropometric parameters of MS patients based on gender 


\section{DISCUSSION}

This is the first study with the largest sample size in Sudanese population evaluating the prevalence of MS among college students in Khartoum state and reporting the prevalence of metabolic risks integrating anthropometric, clinical and biochemical parameters.

The overall prevalence of MS in the sample was $7.8 \%$; this rate is low in comparison with other studies. In Saudi Arabia the prevalence of the syndrome was (31.4 \%), also in a Saudi population using the NCEP-ATPIII criteria, AlNozha et al [8] and Ford et al [9] found an ageadjusted prevalence of $23.9 \%$. Using the data from a nationally representative sample of American citizens derived from a cross-sectional health survey. Alexander et al [10] found a prevalence of $43.5 \%$ among subjects older than 50 years from the data derived from the same survey as Ford et al. Japer et al [11] found a prevalence of $23 \%$ among Arab Americans in their study in 2004. Meigs et al [12] studied a large multi-ethnic cohort demographically representative of the US population and found an overall prevalence of the syndrome in $24 \%$ of the general population, with an inter-ethnic variation of $21-31 \%$. Villegas et al [13] found a prevalence of $20.7 \%$ among Irish middle-aged men and women. Using the WHO definition of metabolic syndrome, Abdul-Rahim et al [14] found a prevalence of $17 \%$ among the Palestinians in the West Bank. Al-Lawati et al [15] in their study of the prevalence of the syndrome among Omani adults found a prevalence of $21 \%$.

In our study represents the MS to be increased in females than males, (8.1\% vs. 7.7 respectively), this agrees with Al-Nozha study which showed prevalence of metabolic syndrome was increased in females than males, and higher in urban than in rural areas.

The leading factors contributing to the metabolic syndrome in Al-Nozha study was low high density lipoprotein, while in our study the blood sugar was the major contributor and was directly proportional with age.

The prevalence of metabolic syndrome in the present study is likely to be less than the estimated prevalence in other studies since the population of this study was younger in age.

The finding in the present study showed that BMI constitutes one of factors that significantly leads to MS. Hedley et al [16] stated that the prevalence of overweight and obesity exceeds
$65 \%$ in the U.S. and that overweight and obese individuals are at a substantially higher risk of having MS, these results have important public health implications. Strategies to combat the increasing prevalence of overweight and obesity that also target those with elevated risk factor profiles, including sedentary habits and cardio respiratory failure, are likely to be the most effective in improving the health of the population.

Physicians at primary health care should be motivated to identify the problem and implement necessary remedial and preventive measures focusing on weight control, increased physical exercise, controlling dyslipidemia, hypertension and diabetes. General population should be educated to raise their consciousness toward their health and the value of screening. They should be oriented toward the risks of obesity and physical inactivity. Control of this syndrome among the population is of vital importance and requires the attention of all health professionals.

\section{Limitations of the study}

Although the present study has yielded many interested findings, one weakness is the limited population which consisted of only first-year undergraduate students in a few Sudanese universities. Therefore, the results do not portray the general trend of MS in the whole of Sudan.

\section{CONCLUSION}

The prevalence of MS among some Sudanese first year college students population is moderately high MS and directly proportional to BMI.

\section{REFERENCES}

1. Grundy SM, Brewer HB, Cleeman JI, Smith SC, Lenfant C. Definition of metabolic syndrome. Report of the National Heart, Lung, and Blood Institute/American Heart Association Conference on scientific issues related to definition. Circulation. 2004; 109: 433-438.

2. Scott CL: Diagnosis, prevention and intervention for the metabolic syndrome. American Journal of Cardiology. 2003; 92: 35-42.

3. Zaki, ME, Mohamed SK, Bahgat KA, Kholoussi SM. Metabolic syndrome components in obese Egyptian children. Ann Saudi Med. 2012; 32(6): 603-610.

4. Executive summary of the third report on the National Cholesterol Education Program (NCEP) expert panel on detection, evaluation, and treatment of high blood cholesterol in adults (adult treatment panel III). JAMA. 2001; 285: 2486-2497. 
5. Isomaa B, Almgren $P$, Tuomi $T$, Forsen $B$, Lahti $K$, Nissen $M$. Cardiovascular morbidity and mortality associated with the metabolic syndrome. Diabetes Care 2001; 24:683-689.

6. Girman CJ, Rhodes T, Mercuri M, Pyorala K, Kjekshus J, Pedersen TR. 4S Group and the AFCAPS/TexCAPS Research Group: The metabolic syndrome and risk of major coronary events in the Scandinavian Simvastatin Survival Study (4S) and the Air Force/Texas Coronary Atherosclerosis Prevention Study (AFCAPS/TexCAPS). Am J Cardiol. 2004; 93(2): 136-141.

7. Bonora E, Kiechl S, Willeit J. Carotid atherosclerosis and coronary heart disease in the metabolic syndrome: prospective data from the Bruneck study. Diabetes Care 2003; 26: 1251.

8. Al-Nozha MM, Al-Khadra A, Arafah MR, Al-Maatouq MA, Khalil M, Khan NB. Metabolic Syndrome in Saudi Arabia. SMJ. 2005; 26(12): 1918-1925.

9. Ford ES, Giles WH, Dietz WH. Prevalence of metabolic syndrome among US adults: finding from the Third National Health and Nutrition Examination Survey. JAMA. 2002; 287: 356-359.

10. Alexander CM, Landsman PB, Teutsch SM, Haffner SM. NCEP defined metabolic syndrome, diabetes mellitus and prevalence of coronary heart disease among
NHANES III participants aged 50 years and older. Diabetes. 2003; 52: 1210-1214.

11. Japer LA, Brown MB, Hammad A, Zhu Q, Herman WH. The prevalence of the metabolic syndrome among Arab Americans. Diabetes Care. 2004; 27: 234-238.

12. Meigs JB, Wilson PWF, Nathan DM, D Agostino RB, Williams $K$, Haffner SM. Prevalence and characteristics of the metabolic syndrome in San Antonio Heart and Framingham Offspring Studies. Diabetes. 2003; 52: 2160-2167.

13. Villegas $R$, Perry IJ, Creagh $D$, Hinchion R, O'Halloran $D$. Prevalence of metabolic syndrome in middle-aged men and women. Diabetes Care. 2003; 26: 31983199.

14. Abdul-Rahim HF, Husseini A, Bjertness E, Giacaman R, Gordon NH, Jervell J. The metabolic syndrome in the West Bank population. An urban-rural comparison. Diabetes Care. 2001; 24: 275-279.

15. Al-Lawati JA, Mohammad AJ, Al-Hinal HQ, Jousilahti P. Prevalence of the metabolic syndrome among Omani adults. Diabetes Care. 2003; 26: 1781-1785.

16. Hedley AA, Ogden CL, Johnson CL, Carroll MD, Curtin $L R$, Flegal KM. Prevalence of overweight and obesity among US children, adolescents and adults 19992002. JAMA. 2004; 291: 2847-2850. 